\title{
Radar-rain-gauge rainfall estimation for hydrological applications in small catchments
}

\author{
Salvatore Gabriele, Francesco Chiaravalloti, and Antonio Procopio \\ CNR-IRPI, Research Institute for Geo-Hydrological Protection, Rende (CS), 87030, Italy \\ Correspondence to: Francesco Chiaravalloti (francesco.chiaravalloti@irpi.cnr.it)
}

Received: 30 November 2016 - Revised: 23 May 2017 - Accepted: 31 May 2017 - Published: 12 July 2017

\begin{abstract}
The accurate evaluation of the precipitation's time-spatial structure is a critical step for rainfall-runoff modelling. Particularly for small catchments, the variability of rainfall can lead to mismatched results. Large errors in flow evaluation may occur during convective storms, responsible for most of the flash floods in small catchments in the Mediterranean area. During such events, we may expect large spatial and temporal variability. Therefore, using rain-gauge measurements only can be insufficient in order to adequately depict extreme rainfall events. In this work, a double-level information approach, based on rain gauges and weather radar measurements, is used to improve areal rainfall estimations for hydrological applications. In order to highlight the effect that precipitation fields with different level of spatial details have on hydrological modelling, two kinds of spatial rainfall fields were computed for precipitation data collected during 2015 , considering both rain gauges only and their merging with radar information. The differences produced by these two precipitation fields in the computation of the areal mean rainfall accumulation were evaluated considering 999 basins of the region Calabria, southern Italy. Moreover, both of the two precipitation fields were used to carry out rainfall-runoff simulations at catchment scale for main precipitation events that occurred during 2015 and the differences between the scenarios obtained in the two cases were analysed. A representative case study is presented in detail.
\end{abstract}

\section{Introduction}

The knowledge of spatial and temporal distribution of rainfalls is of great importance in many fields such as meteorology, agronomy and hydrology. Spatial rainfall variability strongly affects hydrological processes at catchment scale and, in particular, the accuracy of rainfall-runoff model predictions depends on the precision of rainfall estimates (Arnaud et al., 2002; Pechlivanidis et al., 2016). The most widely used sources of rainfall data are rain-gauge networks, which provide direct measurement of precipitation intensity and duration at individual point sites. Spatial interpolation is then necessary to obtain a distributed precipitation field. Several interpolation techniques have been developed (Ball and Luk, 1998; Ly et al., 2013) and they can be classified into two main groups: deterministic methods, such as Thiessen polygon or inverse distance weighting, and geostatistical methods such as ordinary kriging. However, due to the sparse and spot-like data distribution, rain gauges can be too scattered to provide information on the spatial variability of the rainfall with the details required by hydrological models, especially in the case of local convective storms (Bell and Moore, 2000). Even with a high-density rain-gauge network, the retrieving of sufficiently accurate precipitation patterns can be problematic (Peleg et al., 2013). The quantitative estimate of the spatial distribution of rainfall can be improved by coupling rain-gauge information with rainfall measurements provided by weather radars. A meteorological radar is a remote sensing instrument that measures the equivalent reflectivity factor, usually expressed in $\mathrm{mm}^{6} \mathrm{~m}^{-3}$ or in $\mathrm{dBZ}$ 10 times of common logarithm is computed. The measured reflectivity $Z$ is correlated to the water content of the cloud: values of $Z \sim 10-15 \mathrm{dBZ}$ usually indicate precipitation at the ground, which become intense for $Z \geq 40 \mathrm{dBZ}$; deep convection typically takes place for $Z \sim 50 \mathrm{dBZ}$. Reflectivity is then converted into a precipitation rate $R$ using the empirical Marshall-Palmer reflectivity-rainfall $(Z-R)$ power relationship (Austin, 1987). With respect to rain gauges, meteorological radars represent an improvement since they provide widespread spatial coverage at high spatial and tem- 
poral resolution and produce spatially continuous values instead of local measurements. However, meteorological radar exhibits some disadvantages, namely the calibration of the $Z-R$ relationship, whose parameters change from one area to another and depend upon the storm typology, and the absence of a single method universally valid for calibration (Scofield and Kuligowski, 2003). Other important error sources in radar rainfall estimation are ground clutter, rain-induced attenuation, bright-band contamination, beam broadening and anomalous propagation (Borga, 2002; Cunha et al., 2012; Berne and Krajewski, 2013; Park et al., 2016; van de Beek et al., 2016). The presence of complex topography can further amplify some of these uncertainties, and mountainous obstructions can significantly reduce the radar coverage and its monitoring capabilities (Young et al., 1999; Montopoli et al., 2017). For these reasons, rain gauges and weather radars are considered as complementary observation systems and several techniques have been proposed to merge the two kinds of information in order to obtain greater accuracy in areal rainfall estimation and subsequent hydrological modelling results (McKee and Binns, 2016). Some of the used merging methods are mean field bias (MFB) correction, Brandes spatial adjustment (BSA), rangedependent bias (RDB) correction, ordinary kriging $(\mathrm{OK})$ and kriging with external drift (KED). Goudenhoofdt and Delobbe (2009) performed a long-term verification of different used merging methods considering daily rain accumulation from a dense (one gauge per $135 \mathrm{~km}^{2}$ ) network of rain gauges located within $120 \mathrm{~km}$ from a weather radar. They found that KED is the best method to obtain accurate spatial interpolation of rain-gauge values, and the improvement increases for dense rain-gauge networks. Similar results were also pointed out in the paper by Nanding et al. (2015), where different merging methods are compared on an hourly timescale for various rain-gauge network densities and storm types, and KED proved to be the better performing method, especially for a high rainfall threshold amount. In small catchments, gauged data is often poor or unavailable (Hapuarachchi et al., 2011) and, because the sensitivity of runoff modelling to spatial rainfall variability cannot be treated as scale dependent relative to the size of the catchment (Zoccatelli et al., 2010), the use of additional information for a reconstruction of the space rainfall field is important even in these cases.

In the present paper, in order to characterise the effect of the areal rainfall field estimation error on simulated hydrological processes, both KED and rain-gauge interpolation schemes were taken into account. It is well known that, especially in the case of convective events in the Mediterranean area, small basins are prone to flash floods that constitute a major risk to human activity (Chiaravalloti and Gabriele, 2009; Vennari et al., 2016). The aim of this work is to highlight how the use of rain-gauge data only, can prove inadequate in order to reconstruct hydrological phenomena, particularly in small basins. In other words, the spatial variability of precipitation can play an important role in flood modelling even at scale of small catchments.

In this context, taking into account radar information can lead to a substantial improvement in the accuracy of hydrological modelling. In the present paper, in order to estimate the average effect of radar information in the reconstruction of the precipitation field, areal mean rainfall on 999 catchments of the region Calabria, southern Italy, was estimated for the year 2015 with two different ways of calculating the precipitation field: (1) spatial interpolation of rain-gauge data only (using inverse distance weighting method or ordinary kriging), (2) KED merging of rain-gauge and radar surface rainfall intensity (SRI) data.

A more detailed analysis was carried out using the two different precipitation fields as input of a rainfall-runoff model, and the two corresponding hydrological scenarios are reconstructed for the main rainfall events that occurred in Calabria during 2015.

The paper is organised as follows: used rain-gauge and radar data and their processing are described in Sect. 2; results on different areal precipitation fields computed on Calabrian basins and a representative case study of rainfallrunoff modelling on a small catchment are presented in Sect. 3; finally, conclusions in Sect. 4 close the paper.

\section{Available data and procedure}

The rain-gauges data were provided by the Civil Protection of the region Calabria (CPRC), southern Italy. A network of 156 rain gauges, distributed on a surface of $\sim 15200 \mathrm{~km}^{2}$, sends data every $15 \mathrm{~min}$ with a temporal resolution of $1 \mathrm{~min}$. Network configuration, together with the radar position and its optimal operative range, is shown in Fig. 1.

The weather radar is a C-band $(5.6 \mathrm{GHz})$ dual-polarisation Doppler system located at an altitude of $1725 \mathrm{ma.s.1}$. on Mount Pettinascura (Fig. 1). The resolution of the radar polar data is $1^{\circ}$ in azimuth and $150 \mathrm{~m}$ in range. Usually, a weather radar performs a complete $360^{\circ}$ azimuthal scan for a given series of antenna elevation angles. After each scanning rotation, the antenna elevation is changed for the next sounding. The set of data acquired on the different conical surfaces, corresponding to different elevation angles, provides volumetric information on the precipitation field. A typical scan of the Mount Pettinascura radar (MPR) comprises 12 elevations of the antenna, from 0.5 to $90^{\circ}$; a complete volume is acquired every $5 \mathrm{~min}$.

The choice of MPR positioning, which is not optimal due, for example, to the surrounding complex topography and to the increasing height of the radar beam with respect to the ground as the distance from the radar increases, is the result of a compromise to allow for precipitation monitoring on the whole Calabria region. However, although MPR is set in order to work on larger distances, the optimal operative range for the MPR is $\sim 180 \mathrm{~km}$. An accurate mon- 


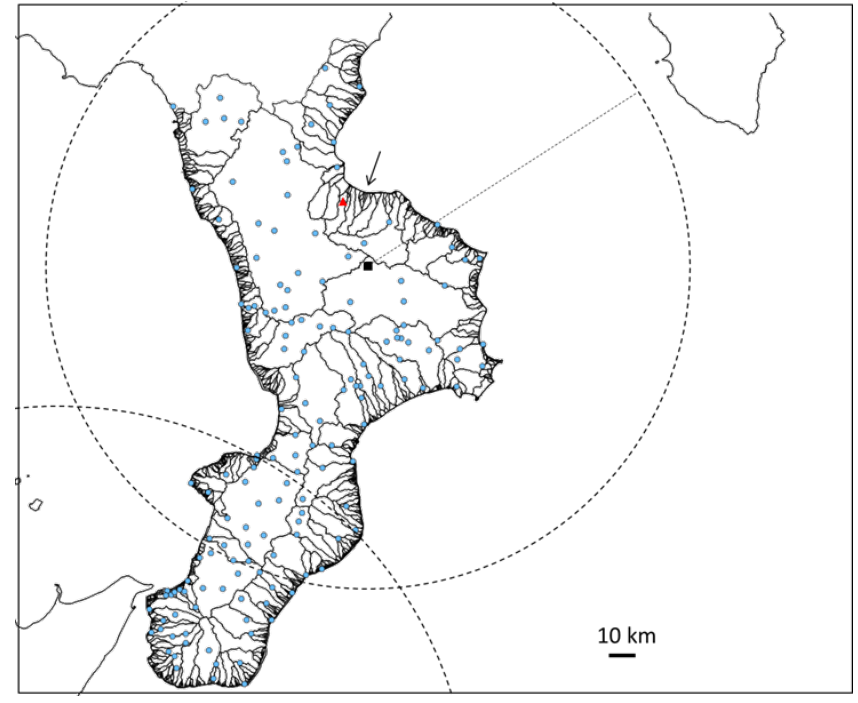

Figure 1. Rain-gauge network and Mount Pettinascura weather radar (black square) with its optimal operative range. The arrow indicates the studied catchment, and the red triangle the nearest rain gauge. The operative range of the Monte Lauro weather radar, in Sicily, is also depicted.

itoring of the entire region is guaranteed by the presence of a similar C-band radar located on Mount Lauro (long $14.836^{\circ} \mathrm{E}$, lat $37.116^{\circ} \mathrm{N}$ ), in Sicily, at an altitude of $980 \mathrm{~m}$, which covers the southern part of the Calabria. These two radars are part of the Italian national radar network, managed by the National Civil Protection Department (NCPD) (Vulpiani et al., 2008). Merging high-resolution volumetric data from weather radars located on Italian territory, the NCPD produces the national mosaic of meteorological products (http://www.protezionecivile.gov.it/jcms/it/mappa radar.wp). During the year 2015, products were provided in near real time and validated by the NCPD, with a temporal resolution of $10 \mathrm{~min}$ on $1 \mathrm{~km} \times 1 \mathrm{~km}$ resolution Cartesian grids. These products include constant altitude plan position indicator (CAPPI; dBZ), which gives a horizontal cross section of reflectivity at 2000, 3000 and 5000 ma.s.l.; Vertical Maximum Intensity (VMI; dBZ), which represents the maximum reflectivity value present on every point's vertical; SRI $\left(\mathrm{mm} \mathrm{h}^{-1}\right)$, which estimates the ground rain rate. The SRI product is computed applying a standard Marshall-Palmer $Z-R$ relationship (Vulpiani et al., 2008, 2012). The 1, 3, 6, 12 and $24 \mathrm{~h}$ accumulated surface rain total (SRT; mm) are also provided.

An analysis of the errors in the radar products furnished by the NCPD is beyond the scope of the present paper, whose main aim is to underline the importance of radar information in hydrological modelling, particularly in small catchments. Weather radar is capable of accurate identification of the positions of precipitation maxima, allowing for an estimate of the rainfall field with a more realistic spatial structure with respect to the information obtained from rain-gauge interpolation. This is especially important for convective events, which can produce very localised rainfalls, often underestimated or not properly identified by rain-gauge networks.

However, the SRI product available for the Calabrian area is affected by major local over- or underestimation when compared to the corresponding rain-gauge point measurements. In order to improve the quantitative estimation of the spatial rainfall fields, SRI data from MPR and rain-gauge measurement of the CPRC network are merged using kriging methods. KED allows one to take into account more additional variables in order to use auxiliary information to improve spatial prediction. In this approach, the rain-gauge data are used as the primary variable and radar data represent the auxiliary information. In other words, it is assumed that radar observations properly capture the pattern of the true precipitation field. Therefore, KED provides an interpolated precipitation field with the correct spatial structure, constrained to the available rain-gauge measurements. In the present study, the KED is done with R, a software for statistical computing, which uses packages for geospatial analysis (R-Project, 2016). The interpolation process is highly automated by using the "autoKrige" function implemented in the Automap and Gstat libraries of R.

The average influence that different spatial rainfall patterns may have on runoff modelling was investigated by comparing the mean areal precipitation on catchments of Calabria, calculated using two different interpolation techniques on rainfall data recorded during the year 2015. A first estimate of the areal precipitation was carried out by interpolating the rain-gauge measures at a sample interval of $30 \mathrm{~min}$ $\left(\mathrm{mm} 30 \mathrm{~min}^{-1}\right)$ with the inverse distance (ID) method (Teegavarapu and Chandramouli, 2005). Cumulative rainfall averaged on a catchment area was then computed for each one of the 999 catchments identified by the Calabrian Basin Authority $\left(R_{i}^{\mathrm{ID}}(t), \mathrm{mm} \mathrm{km}^{-2}, i=1, \ldots, 999\right)$. Catchment dimension varies from less than $1 \mathrm{~km}^{2}$ up to about $2500 \mathrm{~km}^{2}$. In order to retrieve a more detailed pattern for the areal rainfall field, the cumulative radar rainfall estimates were computed starting from the three corresponding SRI data available in each $30 \mathrm{~min}$ sample interval, and merged with rain-gauge rainfall through the KED method. Mean rainfall $R_{i}^{\mathrm{KED}}(t)$ for each catchment was then calculated. The temporal averages $R_{i}^{\mathrm{ID}}=\left\langle R_{i}^{\mathrm{ID}}(t)\right\rangle_{t}$ and $R_{i}^{\mathrm{KED}}=\left\langle R_{i}^{\mathrm{KED}}(t)\right\rangle_{t}$ were computed and, finally, the quantity $\Delta R(i)=100 \frac{R_{i}^{\mathrm{KED}}-R_{i}^{\mathrm{ID}}}{R_{i}^{\mathrm{KED}}}$ was obtained for each catchment.

A detailed analysis of the influence of radar information in hydrological simulations was performed with accurate rainfall-runoff simulations of the heavier precipitation events occurred in 2015. The used model is a semi-distributed continuous model presented by Brocca et al. (2011) as an improvement of the one developed by Corradini et al. (1995) for the transformation of rainfall into direct outflow. In this approach, a soil water balance model, which dynamically takes 


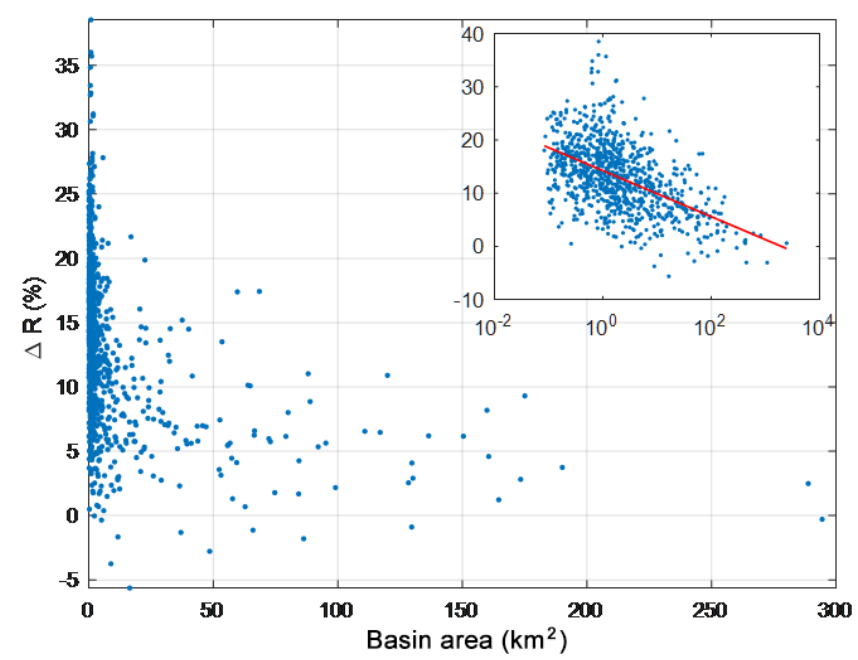

Figure 2. Difference $\Delta R$ between mean areal rainfall calculated with KED and ID procedures, described in the text, on Calabrian catchments, as a function of the basin's area. A peak of about $40 \%$ for small catchments was detected. In the box, the same data are plotted in semi-logarithmic scale with a logarithmic fit in order to underline the decreasing trend of $\Delta R$.

into account the soil moisture state of the catchment, was added. Both precipitation fields, obtained by spatial interpolation of rain-gauge data only or via KED, with time resolution of $30 \mathrm{~min}$, were used as inputs of the model, and two different scenarios were obtained for any studied event.

\section{Results}

\subsection{Analysis for all the Calabrian catchments}

The results obtained for the mean areal precipitation on Calabrian catchments, calculated from the above-described procedure, are shown in Fig. 2. The difference $\Delta R$ between results obtained, taking into account rain-gauge and radar data or rain-gauges only, increases for small basins with peaks of about $40 \%$ for the smaller ones. For catchments above $\sim 300 \mathrm{~km}^{2}$, the two different adopted interpolation methods produce similar mean areal precipitation. Similar results are obtained if the ID interpolation method is replaced with other techniques that take into account only the rain-gauge data, as, for example, ordinary kriging (a geostatistical method, which deals with the spatial interpolation of a random field from observations at several locations; Wackernagel, 2013) or Thiessen polygons. It is worth noting that KED interpolation produces a higher mean areal precipitation in small basins. Furthermore, it seems to suggest that the usage of rain-gauges only may bring a strong underestimation in the magnitude of the floods in hydrological processes on small catchments.

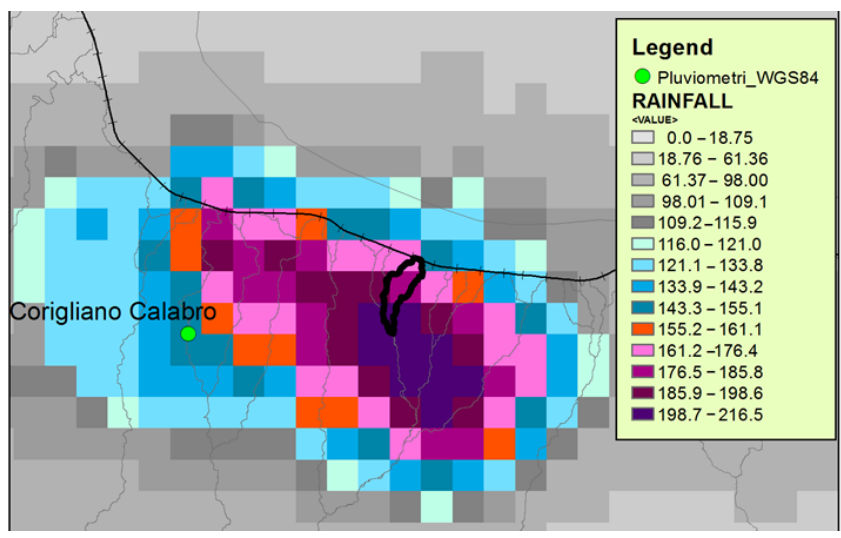

Figure 3. The 12 August 2015 case study. Cumulative 00:0008:00 GMT radar rainfall (darker colours mean heavier rainfalls) and Corigliano rain gauge (green circle).

\subsection{Event of 12 August 2015}

The previous results are also confirmed by the rainfall-runoff simulation of the studied precipitation events. The use of the spatial rainfall field obtained through KED as an input of the model generally leads to greater flows. A typical situation is the one that occurred on 12 August 2015, when a heavy rainfall event hit an area of about $100 \mathrm{~km}^{2}$ between the towns of Corigliano and Rossano, in the northeast of Calabria. The rain gauge located closest to the interested area measured a cumulative rainfall exceeding $200 \mathrm{~mm}$ in the time interval 02:00-08:00 GMT. The spatial structure of the rainfall field, obtained by summing corresponding SRI data, clearly showed that this rain gauge was on the edge with respect to the zone of maximum rainfall intensity (Fig. 3). The rainfall-runoff simulation considers a very small basin, $\sim 1.3 \mathrm{~km}^{2}$, named Fosso Pantano, $8 \mathrm{~km}$ away from the nearest rain gauge. The hydrological response, in the two precipitation hypotheses calculated from rain gauges only (ID), and rainfall calculated from radar and rain gauges (KED) were compared. In this case study, due to the limited areal extent of the basins (less than $25 \mathrm{~km}^{2}$ ), the hydrological model (Brocca et al., 2011) was applied in the lumped version, that is, considering the river basin as a system that responds homogeneously. In Fig. 4 the hydrograph floods resulting from the "lumped" fit of the two precipitation fields are compared. The maximum flood peak flow, using only rain gauges, was equal to $5 \mathrm{~m}^{3} \mathrm{~s}^{-1}$ while, with rainfall field derived from radar, the estimated flow rate was equal to $30 \mathrm{~m}^{3} \mathrm{~s}^{-1}$, which is 6 times larger. The $30 \mathrm{~m}^{3} \mathrm{~s}^{-1}$ value was verified in situ through a submerged culvert with a flow capacity of $25 \mathrm{~m}^{3} \mathrm{~s}^{-1}$. The significant difference was expected given the marginal position of the rain gauge of Corigliano compared with the centre of the hydrometeor. 
(a)

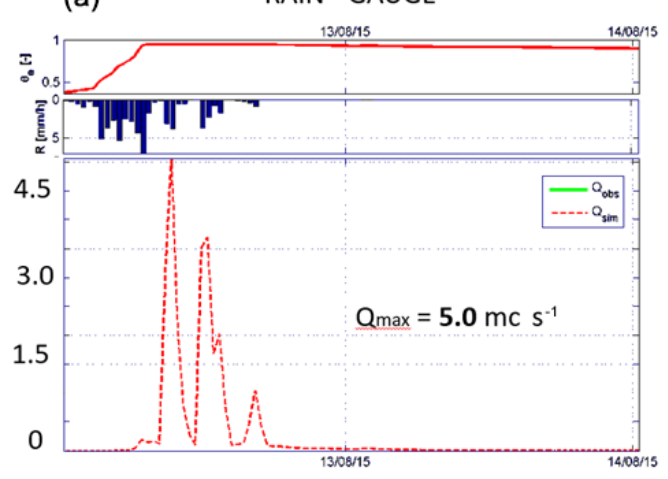

(b)

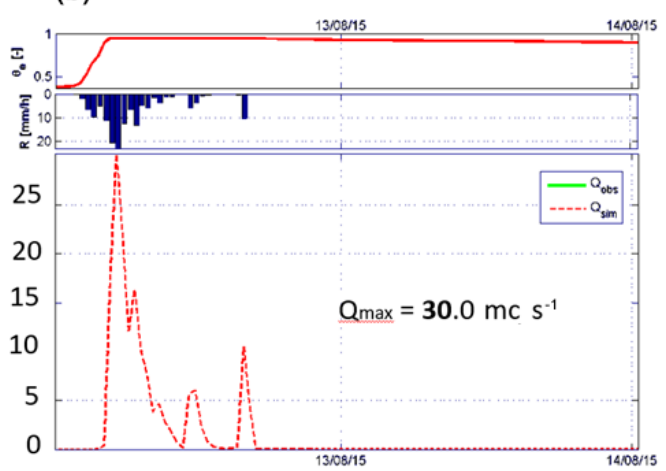

Figure 4. The hydrological response of the Fosso Pantano basin using rain gauge alone (a) and radar with rain-gauge data (b).

\section{Conclusions}

In rainfall-runoff modelling, a correct evaluation of rainfall fields in space and time is essential and this paper tried to investigate the importance of taking into account radar information in evaluating a spatially detailed rainfall field when dealing with small basins in hydrological processes. Using rain-gauge and weather radar data recorded during the year 2015 on the Calabrian region catchments, it was shown how the use of rain gauges only may lead to a strong underestimation of the average areal rainfall on small basins, with a high risk of floods underestimation for small catchments. In fact, for basins with an area of $\sim 1 \mathrm{~km}^{2}$, mean underestimations of average areal rainfall up to $40 \%$ were detected. With the increasing of the basin area, this mean underestimation decreases, and for areas greater than $300 \mathrm{~km}^{2}$ the introduction of weather radar information does not produce substantial changes in the mean areal rainfall estimation. Through rainfall-runoff simulations at catchment scale, the absence of weather radar information in the evaluation of spatial rainfall fields was proven to have a huge impact in the reconstruction of hydrological scenarios. A case study on a very small basin of about $1.3 \mathrm{~km}^{2}$ was presented to show that underestimation up to $80 \%$ in the maximum flood peak flow estimation is possible. In conclusion, the results shown in this work highlight the importance of the usage of weather radar information in order to correctly estimate the spatial rainfall field for hydrological modelling, especially for small basins.

Data availability. Data used in the preset work are provided by the Calabrian Regional Environmental Protection Agency (Functional Multirisk Center of the region Calabria). These data are not freely available and we are not allowed to provide access to them.

Competing interests. The authors declare that they have no conflict of interest.
Special issue statement. This article is part of the special issue "Hydro-related hazardous events and their consequences in the Mediterranean area: knowledge management adaptation". It is a result of the 15th Plinius Conference on Mediterranean Risks, Giardini Naxos, Italy, 8-11 June 2016.

Acknowledgements. This work was co-founded by RFI SpA, the Italian Railway Network, with the RAMSES (RAilway Meteorological SEcurity System) project. We thank the Calabrian Regional Environmental Protection Agency (Functional Multirisk Center of the region Calabria) for providing the used data.

Edited by: Athanasios Loukas

Reviewed by: Nicolas R. Dalezios and three anonymous referees

\section{References}

Arnaud, P., Bouvier, C., Cisneros, L., and Dominguez, R.: Influence of rainfall spatial variability on flood prediction, J. Hydrol., 260, 216-230, https://doi.org/ 10.1016/S0022-1694(01)00611-4, 2002.

Austin, P. M.: Relation between measured radar reflectivity and surface rainfall, Mon. Weather Rev., 115, 1053-1070, https://doi.org/10.1175/15200493(1987)115<1053:RBMRRA>2.0.CO;2, 1987.

Ball, J. E. and Luk, K. C.: Modeling spatial variability of rainfall over a catchment, J. Hydrol. Eng., 3, 122130, https://doi.org/10.1061/(ASCE)1084-0699(1998)3:2(122), 1998.

Bell, V. A. and Moore, R. J.: The sensitivity of catchment runoff models to rainfall data at different spatial scales, Hydrol. Earth Syst. Sci., 4, 653-667, https://doi.org/10.5194/hess-4-653-2000, 2000.

Berne, A. and Krajewski, W. F.: Radar for hydrology: Unfulfilled promise or unrecognized potential?, Adv. Water Resour., 51, 357-366, 2013.

Borga, M.: Accuracy of radar rainfall estimates for streamflow simulation, J. Hydrol., 267, 26-39, https://doi.org/10.1016/S00221694(02)00137-3, 2002. 
Brocca, L., Melone, F., and Moramarco, T.: Distributed rainfallrunoff modelling for flood frequency estimation and flood forecasting, Hydrol. Process., 25, 2801-2813, 2011.

Chiaravalloti, F. and Gabriele, S.: Vibo Valentia flood and MSG rainfall evaluation, Atmos. Res., 93, 286-294, 2009.

Cunha, L. K., Mandapaka, P. V., Krajewski, W. F., Mantilla, R., and Bradley, A. A.: Impact of radar-rainfall error structure on estimated flood magnitude across scales: An investigation based on a parsimonious distributed hydrological model, Water Resour. Res., 48, W10515, https://doi.org/10.1029/2012WR012138, 2012.

Corradini, C., Melone, F., and Ubertini, L.: A semi-distributed model for direct runoff estimate, in: Applied Simulation and Modelling, edited by: Hamza, M. H., IASTED Acta Press, Anaheim, CA, 541-545, 1995.

Goudenhoofdt, E. and Delobbe, L.: Evaluation of radar-gauge merging methods for quantitative precipitation estimates, Hydrol. Earth Syst. Sci., 13, 195-203, https://doi.org/10.5194/hess13-195-2009, 2009.

Hapuarachchi, H. A. P., Wang, Q. J., and Pagano, T. C.: A review of advances in flash flood forecasting, Hydrol. Process., 25, 27712784, 2011.

Ly, S., Charles, C., and Degré, A.: Different methods for spatial interpolation of rainfall data for operational hydrology and hydrological modeling at watershed scale. A review, Biotechnology, Agronomy, Society and Environment, 17, 392-406, 2013.

McKee, J. L. and Binns, A. D.: A review of gaugeradar merging methods for quantitative precipitation estimation in hydrology, Can. Water Resour. J., 41, 186-203, https://doi.org/10.1080/07011784.2015.1064786, 2016.

Montopoli, M., Roberto, N., Adirosi, E., Gorgucci, E., and Baldini, L.: Investigation of Weather Radar Quantitative Precipitation Estimation Methodologies in Complex Orography, Atmosphere, 8, 34, https://doi.org/10.3390/atmos8020034, 2017.

Nanding, N., Rico-Ramirez, M. A., and Han, D.: Comparison of different radar-raingauge rainfall merging techniques, J. Hydroinform., 17, 422-445, https://doi.org/10.2166/hydro.2015.001, 2015.

Park, T., Lee, T., Ahn, S., and Lee, D.: Error influence of radar rainfall estimate on rainfall-runoff simulation, Stoch. Env. Res. Risk A., 30, 283-292, 2016.

Pechlivanidis, I. G., McIntyre, N., and Wheater, H. S.: The significance of spatial variability of rainfall on simulated runoff: an evaluation based on the Upper Lee catchment, UK, Hydrol. Res., nh2016038, https://doi.org/10.2166/nh.2016.038, 2016.

Peleg, N., Ben-Asher, M., and Morin, E.: Radar subpixel-scale rainfall variability and uncertainty: lessons learned from observations of a dense rain-gauge network, Hydrol. Earth Syst. Sci., 17, 2195-2208, https://doi.org/10.5194/hess-17-2195-2013, 2013.
R-Project: R: A Language and Environment for Statistical Computing, Development Core Team, R Foundation for Statistical Computing, Vienna, Austria, available at: http://www.R-project.org, last access: 29 June 2016.

Scofield, R. A. and Kuligowski, R. J.: Status and outlook of operational satellite precipitation algorithms for extreme-precipitation events, Weather Forecast., 18, 1037-1051, https://doi.org/10.1175/15200434(2003)018<1037:SAOOOS>2.0.CO;2, 2003.

Teegavarapu, R. and Chandramouli, V.: Improved weighting methods, deterministic and stochastic data-driven models for estimation of missing precipitation records, J. Hydrol., 312, 191-206, 2005.

van de Beek, C. Z., Leijnse, H., Hazenberg, P., and Uijlenhoet, R.: Close-range radar rainfall estimation and error analysis, Atmos. Meas. Tech., 9, 3837-3850, https://doi.org/10.5194/amt-9-38372016, 2016.

Vennari, C., Parise, M., Santangelo, N., and Santo, A.: A database on flash flood events in Campania, southern Italy, with an evaluation of their spatial and temporal distribution, Nat. Hazards Earth Syst. Sci., 16, 2485-2500, https://doi.org/10.5194/nhess16-2485-2016, 2016.

Vulpiani, G., Pagliara, P., Negri, M., Rossi, L., Gioia, A., Giordano, P., Alberoni, P. P., Cremonini, R., Ferraris, L., and Marzano, F. S.: The Italian radar network within the national early-warning system for multi-risks management, Fifth European Conference on Radar in Meteorology and Hydrology, Helsinki, Finland, 30 June-4 July 2008.

Vulpiani, G., Montopoli, M., Passeri, L. D., Gioia, A. G., Giordano, P., and Marzano, F. S.: On the use of dual-polarized C-band radar for operational rainfall retrieval in mountainous areas, J. Appl Meteorol. Clim., 51, 405-425, 2012.

Wackernagel, H.: Multivariate geostatistics: An introduction with applications, Springer Science \& Business Media, 2013.

Young, B., Nelson, B. R., Bradley, A. A., Smith, J. A., Peters-Lidard, C. D., Kruger, A., and Baeck, M. L.: An evaluation of NEXRAD precipitation estimates in complex terrain, J. Geophys. Res., 104, 19691-19703, https://doi.org/10.1029/1999JD900123, 1999.

Zoccatelli, D., Borga, M., Zanon, F., Antonescu, B., and Stancalie, G.: Which rainfall spatial information for flash flood response modelling? A numerical investigation based on data from the Carpathian range, Romania, J. Hydrol., 394, 148-161, 2010. 